Canadian University Music Review

Canadian University Music Review

Revue de musique des universités canadiennes

\title{
Roads Taken and Retaken: Foreground Ambiguity in Chopin's Prelude in A-flat Op. 28, No. 17
}

\section{Kenneth DeLong}

Volume 11, numéro 1, 1991

URI : https://id.erudit.org/iderudit/1014829ar

DOI : https://doi.org/10.7202/1014829ar

Aller au sommaire du numéro

Éditeur(s)

Canadian University Music Society / Société de musique des universités canadiennes

ISSN

0710-0353 (imprimé)

2291-2436 (numérique)

Découvrir la revue

Citer cet article

DeLong, K. (1991). Roads Taken and Retaken: Foreground Ambiguity in

Chopin's Prelude in A-flat Op. 28, No. 17. Canadian University Music Review /

Revue de musique des universités canadiennes, 11(1), 34-49.

https://doi.org/10.7202/1014829ar

All Rights Reserved (C Canadian University Music Society / Société de musique des universités canadiennes, 1991
Ce document est protégé par la loi sur le droit d'auteur. L’utilisation des services d'Érudit (y compris la reproduction) est assujettie à sa politique d'utilisation que vous pouvez consulter en ligne.

https://apropos.erudit.org/fr/usagers/politique-dutilisation/ 


\section{ROADS TAKEN AND RETAKEN: FOREGROUND AMBIGUITY IN CHOPIN'S PRELUDE IN A-FLAT, OP. 28, NO. 17}

\section{Kenneth DeLong}

To anyone over the age of say, thirty-five, it is an increasingly poignant condition of existence to be able to look back over the course of one's life and to marvel at the eventual significance of decisions taken long ago which at the time seemed to be of relatively little importance. Cumulatively, these decisions, often made in haste, determine the ultimate shape of one's life, a process of unfolding as compelling as it remains mysterious. It is the question of life's choices, of the necessity and consequence of one's choices, that the poet Robert Frost treats in his well-known poem "The Road Not Taken," which contains the familiar words:

Two roads diverged in a yellow wood,

And sorry I could not travel both

And be one traveler ...

And both that morning equally lay

In leaves no step had trodden black.

Oh, I kept the first for another day!

Yet knowing how way leads on to way,

I doubted if I should ever come back. (Frost 1970: 26)

The central metaphor of the poem is, of course, the parallelism between the road we travel by foot and the path of life. But the special force and immediacy of the poem stems not so much from the basic image itself than from the use of this image to underline and to bring into focus one of life's essential truisms: that decisions made cannot be unmade, and that the taking of one fork in the road of life usually means that the other must remain forever unexplored-a feature of our common human existence that must ultimately be accepted and reconciled with our most personal dreams.

It is perhaps fortunate that in this respect art does not necessarily mirror life. For the matter of a return to a point previously arrived at and the opportunity for a second look-to make changes along the path in light of experience-are essential to the properties of both balance and variety found in many pieces of music. The recapitulation in a sonata-form movement, the ornamented repeat of a da capo aria, the varied return of the A section of a ternary form piano piece are 
only some of the more obvious instances of opportunities regained; and it is often in the comparing of such expositions with their recapitulations that we discover much that is important to the ultimate understanding of a given work.

These "second chances" sometimes involve a re-thinking of a musical point that initially contained, explicitly or potentially, some measure of ambiguity either in harmonic implication or some other aspect of musical syntax. The clarifying or exploiting of such ambiguous points later in a work can have a profound effect upon its underlying structure and, ultimately, upon its meanings as a work of art. A familiar instance is the renegade $\mathrm{C}$-sharp that occurs in the opening measures of the first movement of Beethoven's Eroica symphony. Initially an unexplained cloud on the harmonic horizon and a temptation to taste forbidden modulatory fruit, it is first rejected in a swift return to the tonic key. Only in the recapitulation, when the forbidden fruit is plucked in the form of an implied enharmonic change from C-sharp to D-flat-a reinterpretation that initiates the ensuing modulation to $\mathrm{F}$ major-is the initial ambiguity finally resolved in a more complex, musically enriched synthesis that embraces both syntactical interpretations. ${ }^{1}$ (Epstein 1979: 120-21)

Frequently these moments of ambiguity are explored as points of humour, rather like a musical pun. An instance of this can be seen, for example, in the minuet movement of Haydn's String Quartet in B minor, Op. 33, No. 1 (see Example 1). Here measure eight forms the climax of four preceding measures in which the F-sharp in the first violin is hammered out, insistently and unambiguously, as the dominant of B minor. No hint of syntactical ambiguity, no potential fork in the grammatical road, can be anticipated here. In fact, it is the overwhelming grammatical clarity of this moment that imbues the ensuing events with humour and makes them a genuine surprise to the unsuspecting listener. For the F-sharp is quitted not as a chord tone but an appoggiatura to the following $G$ (despite the absence of any background harmonic dissonance), which in turn leads to a quick modulation to D major. ${ }^{2}$ The humour of this moment lies the in the momentary harmonic disorientation which occurs when the unambiguous F-sharp is suddenly presented in a different light, introducing an element of ambiguity in an otherwise straightforward passage and with it a witty, amusing moment.

\footnotetext{
${ }^{1}$ A similar instance of the exploitation of a syntactical ambiguity, one that has equally deep resonances within the musical structure, can be seen in the first movement of Beethoven's Symphony No. 4 in B-flat major. Here the G-flat in measure seventeen of the introduction, heard initially as bVI of B-flat major, is quitted as F-sharp, the domination of B minor. That this unexpected turn in the road was not just an accident or a passing harmonic caprice is evident from the return to the very same musical context toward the end of the development, where this same harmonic fork is again presented, this time leading to the orthodox dominant and, eventually, the recapitulation.

${ }_{2}^{2}$ While it may appear strange to refer to the F-sharp in measure eight as an appoggiatura, it is in fact the presence of the specific rhythmic conventions of the classical appoggiatura, with its characteristic slurred stress/release, that is crucial in directing the ear to accept the $G$ in measure eight as a chord note and thereby indicating the harmonic shift in the direction of $\mathrm{D}$ major.
} 
Scherzando Allegro
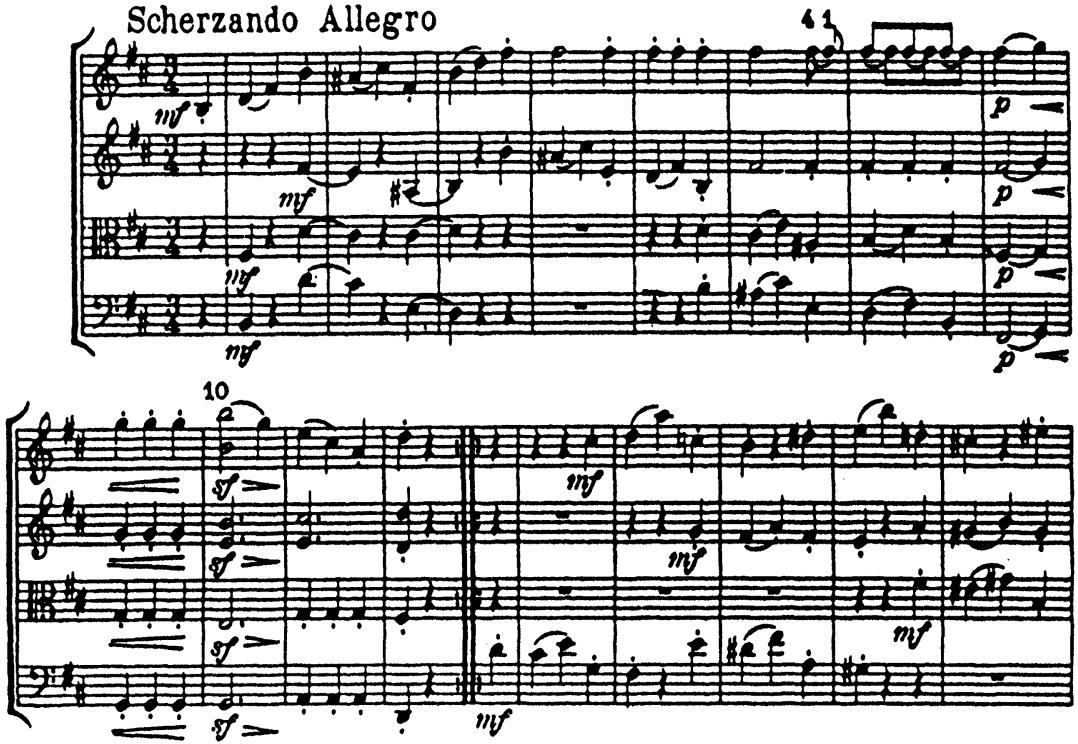

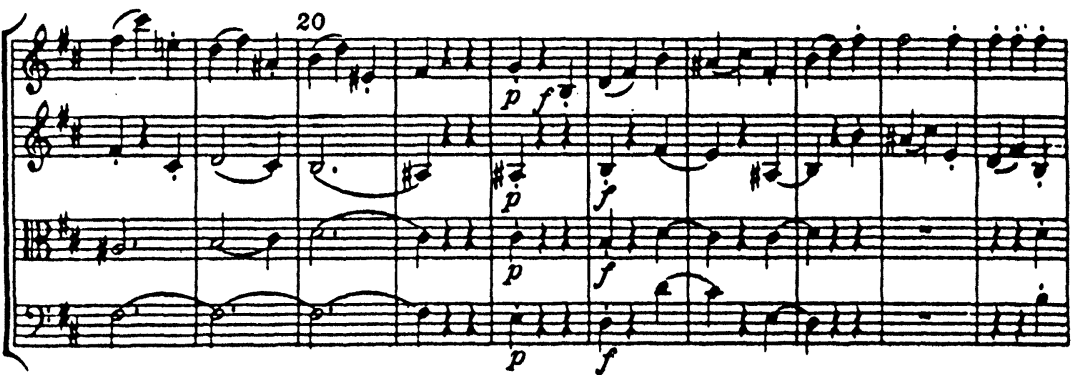

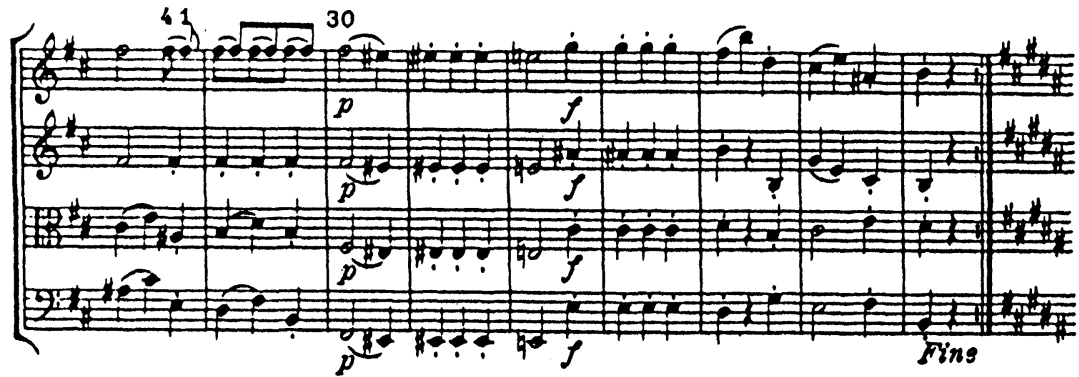

Example 1: Haydn, String Quartet in B minor, op. 33, no. 1, III, mm.1-36. 
The initial surprise, the turning of something clear and unambiguous into a moment of ambiguity and the taking of an unanticipated fork in the harmonic road, is of course only the set- up for the second time the listener encounters this passage. When it returns in the recapitulation of this rounded binary scherzo, Haydn carries his grammatical pun one stage farther. The second time through this passage, as the music approaches measure thirty, the listener's expectations, conditioned by the first playing to expect the unexpected, are rather different: will the F-sharp be treated as expected the first time, as a proper dominant; or will there by some new, yet unexplored further ambiguity? The anticipation of the choice to be made, of which fork in the road will be taken, is crucial to the humour of the passage. Haydn again treats the apparently unambiguous Fsharp as if it were an appoggiatura, but this time it is resolved downwards to an E-sharp (in itself a surprise), presumably the leading tone of F-sharp minor. ${ }^{3} \mathrm{He}$ then compounds grammatical felony with felony by moving down still farther to an E-natural, rendering the previous E-sharp syntactically ambiguous (having been approached as a leading tone but not left as one) and apparently entering a new realm based upon a different type of musical logic wherein any note can follow any other note as long as it is a semitone from the previous note. Traditional tonal grammar, normative to the work as a whole, seems for a moment to be suspended. Only in the following measure (m. 32) is the E-natural absorbed into conventional grammar as a member of a diminished-seventh harmony of B minor. Haydn's logic in treating this unusual moment - a straightforward and compelling logic, if unconventional musically-seems to be that what goes up can also come down, and what goes down can go still farther down. This is not the normal logic of tonal grammar but a different way of thinking, one that arises out of a moment of grammatical ambiguity (where none seemed originally to exist) and which is ultimately integrated into the larger whole through the rationalizing "commentary" on the situation provided by the varied repeat in the recapitulation.

A more complicated instance of foreground ambiguity, with a deeper resonance within the structure of the music, can be seen in Schubert's second Harfenspieler song from Goethe's Wilhelm Meister. The first section of the song presents the opening stanza twice, each time in the form of an antecedent/consequent pairing in which the consequent phase is the same, forming an A B C B structure melodically. The first of these parallel consequent phrases serves the function of

\footnotetext{
${ }^{3}$ It would, of course, be possible also to hear the E-sharp as $\mathrm{F}$ natural, as a passing tone to the subsequent $\mathrm{E}$. This interpretation is, however, only evident in retrospect (after the move to $\mathrm{E}$ ). When first heard, the E-sharp sounds like the sharpened fourth degree of the scale, presumably the reason Haydn notated in that way; it is only after the move to the subsequent unexpected $E$ natural that the E-sharp would naturally be heard as a chromatic passing tone-the central factor in the ambiguity of the entire passage.
} 

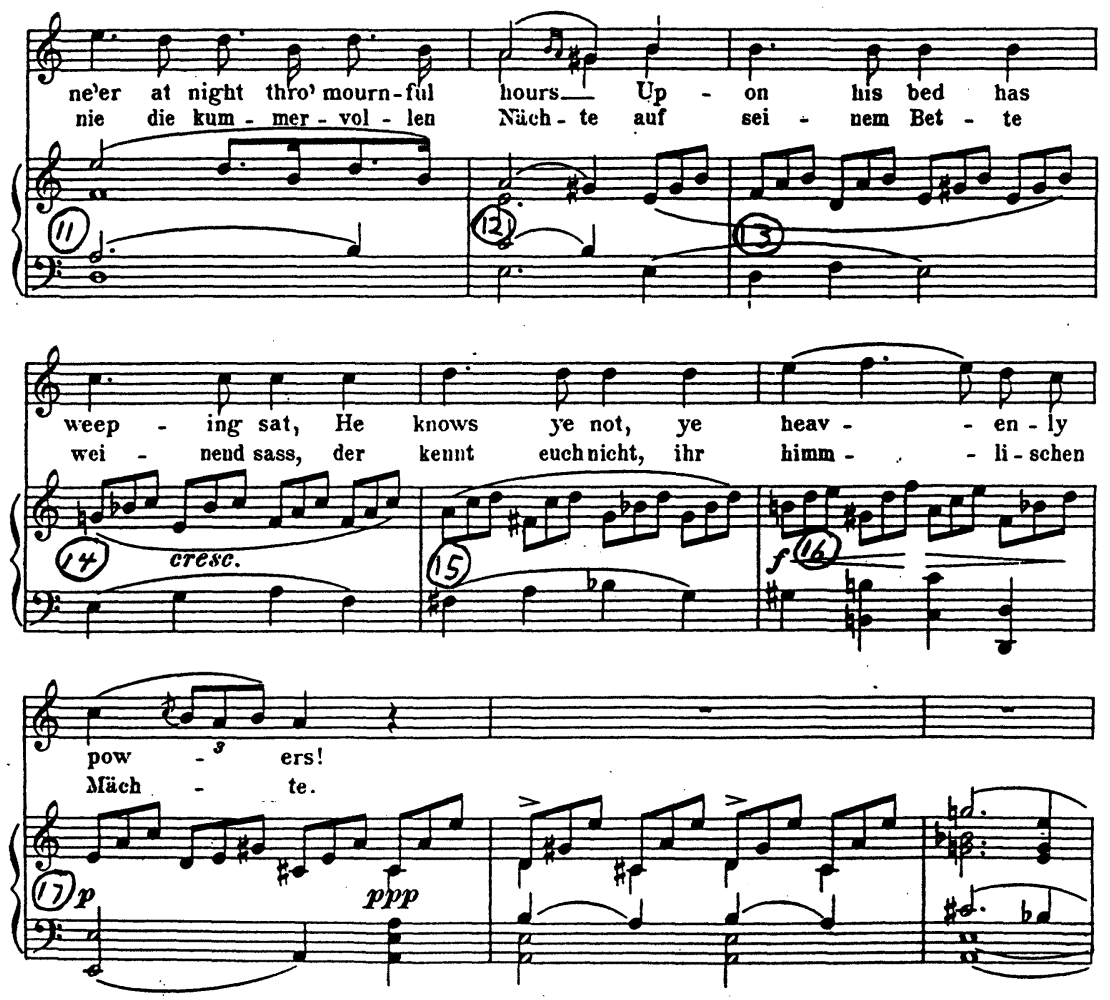

Example 2: Schubert, “Wer nie sein Brot,” mm.11-17.

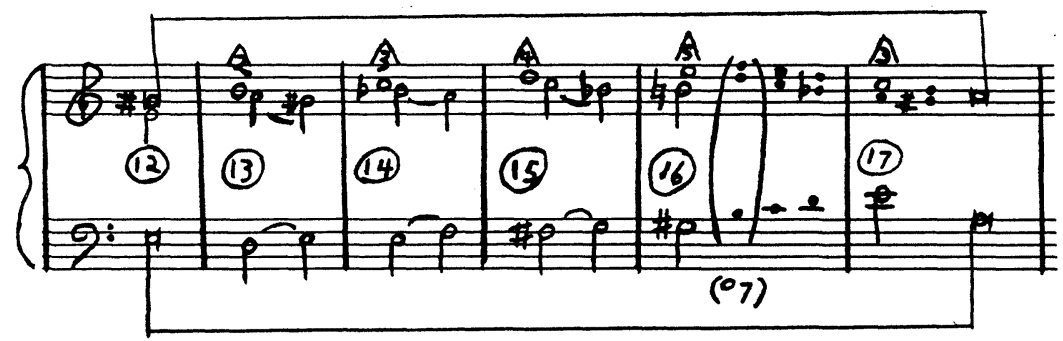

Example 2a: Schubert, "Wer nie sein Brot," mm.11-17, reduction. 
completing the A minor implications of its antecedent, but does so by a harmonically circuitous route, in itself a striking feature of the song in light of the stark simplicity of the opening phrase. As a musical evocation of the heartfelt cry of the pathetic harper, Schubert treats this consequent phrase (see Example $2, \mathrm{~mm} .12-17$ ) as a modulatory sequence that rises by step, lightly tonicizing the keys of $\mathrm{F}$ major and $\mathrm{G}$ minor. The melody rises correspondingly, reaching to a climactic high $\mathrm{F}$ before falling to the cadence, the pathos of the text underlined by the Neapolitan harmony (see Example 2a).

On the surface the passage is perfectly straightforward, with no obvious potential for harmonic or melodic manipulation and no inherent ambiguity in matters of harmony, metre, or melody. However, a more detailed syntactical inspection of the harmony reveals several small irregularities. The initial member of the sequence (m. 13) has an internal harmony of ii-V, but the pattern changes with the following measure to an internal harmony of V-I. Also, the dominant harmony at the end of measure thirteen is not resolved but is followed by the dominant of $\mathrm{F}$ major, a sudden shift-not a resolution - which is smoothed over by the repeated $\mathrm{E}$ in the bass and by the stepwise motion above it. Moreover, the precise pedigree of the sequence is unclear. If it is a rising modulatory sequence diatonic to A minor, the background key and eventual goal, the chord of resolution in measure fifteen should be $\mathrm{G}$ major, not $\mathrm{G}$ minor. Thus although the passage begins with the key of A minor as both the foreground and background key, by the end of measure fifteen $\mathrm{F}$ major has begun to assert itself as the background key of reference for the sequence, both through the stress upon the dominant of $\mathrm{F}$ in measure fourteen and through the natural, diatonic relationship between the keys of F major and G minor, heard in direct juxtaposition as I and ii of $\mathrm{F}$ major. The $\mathrm{A}$ minor cadence at the end of the phrase thus acquires an ambiguous status as either the third member of a rising sequence in $F$ major ( $F$ major-I; G minor-ii; A minor-iii), or a simple return to the original tonic. In context it is difficult to say which is the primary intention. These details pass virtually unnoticed because of the strength of the rising sequence, but like the Beethoven example mentioned above, they form a slight blur on the harmonic horizon.

The syntactical oddities of harmonic detail just mentioned, observable only from a close reading of the foreground, raise a question about the true background key and with it the possibility for different harmonic interpretation on a subsequent occasion. The context for ambiguity has thus been created, one which Schubert exploits and, I believe, rationalizes in his second run at this passage (see Example $2 b$ ). Except for the octave doubling of the left hand, the second presentation of this consequent phrase ( $\mathrm{mm}$. 24-30) opens as the first, driving upwards through the same series of sequences which lightly touch upon the keys of $F$ and $G$. This time, however, the mode of measure twenty-seven is major, not minor, and the high $\mathrm{F}$, taken initially as an expressive, high arching semitone above the dominant, is here transformed into a tonic through the re-interpretation of 


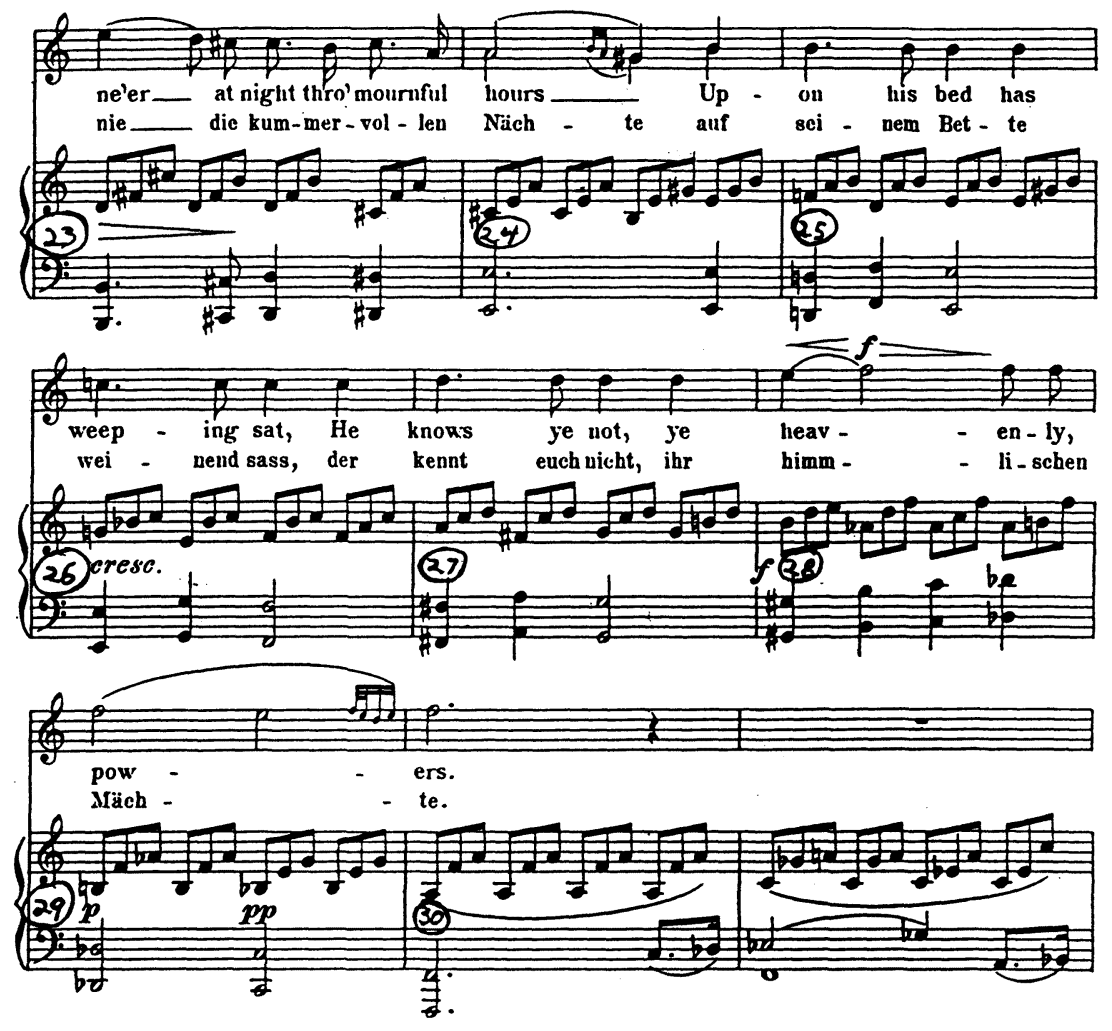

Example 2b: Schubert, "Wer nie sein Brot," mm.23-30.

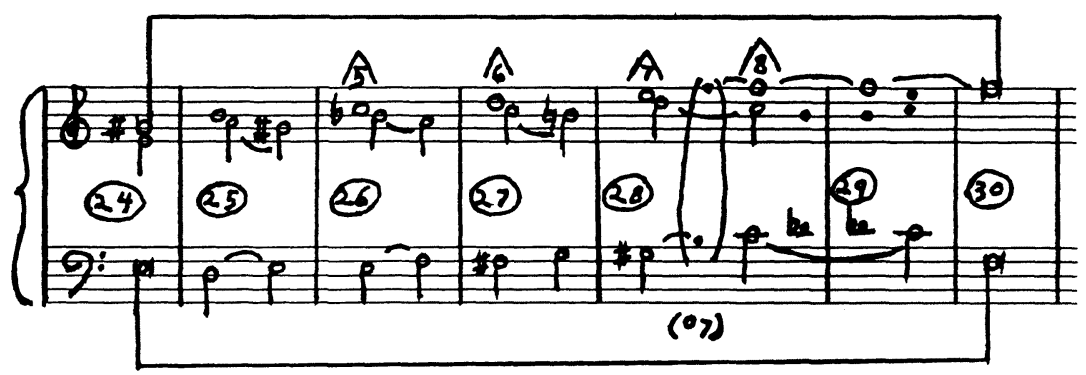

Example 2c: Schubert, "Wer nie sein Brot," mm.23-30, reduction. 
diminished-seventh harmony as vii07/ $\mathrm{V}$ of $\mathrm{F}$ major. The whole passage now traces a clear ascending stepwise line in the treble reaching from dominant to tonic in F major (see Example 2c).

The slight ripples on the harmonic foreground mentioned previously have now penetrated the harmonic background level as a rationalization of ambiguities that were previously present in the foreground, or if you will, as the result of taking the other fork in the original harmonic path. But there is also a double irony or pun here. The most striking moment in the first passage occurs in measure thirteen, which, as already mentioned, deflects the harmony toward F major, the full implications of which are only realized the second time. The second time (mm. 26-28) the sequence is diatonic to A minor, referring, perhaps, to the original harmonic destination,but this time Schubert, or perhaps the "heavenly powers," (mm. 28-29) takes the music to $F$ major. The first version of the sequence thus rationalizes the eventual movement to $F$ major, while the second version (mm. 26-28) confirms the normality of the original A minor-in the words of W.S. Gilbert, "a most ingenious paradox."
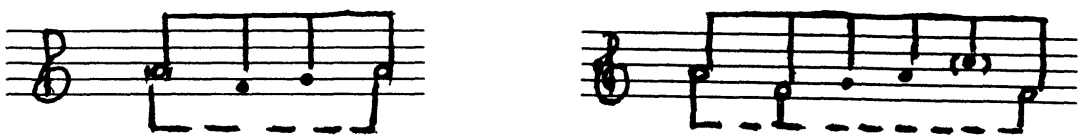

Example 2d: Schubert, "Wer nie sein Brot," mm.11-17 amd 23-30, tonic guide tones.

These musical examples both contain what William Empson in his book Seven Types of Ambiguity refers to as instances of puns or, in his classification, ambiguities of the third type (Empson 1953). In his discrimination among the various types of ambiguities, ordered from the simplest to the most complex, Empson describes such puns as situations in which "there could be a puzzle as to what the author meant, in that alternative views might be taken without sheer misreading" (Empson 1953: x). Empson identifies these situations as instances where an author "is not merely using one thing to illustrate another, but is interested in two things at once, and is making them illustrate one another mutually" (ibid: 112). Even accepting the inherent dangers of applying the terms of literary criticism to music, Empson's definition describes quite precisely the nature of the reciprocal relationship between these two passages of the Schubert song: the first a commentary upon the second and vice versa. In these examples the issue of harmonic ambiguity arises not from moments of easily perceived tonal instability or a harmonically hazy context; rather it arises from a context of stability, and thereby brings into relief the presence of a potential fork in the harmonic road and the opportunity for new or further exploration. In describing such situations, William Thomson comments that "Ambiguity enters the musical scene when a collection of events at one hierarchic level produces a next broader level that bears more than one potential meaning" (Thomson 1983: 7). In the case 
of the Haydn quartet, the possibility of syntactical ambiguity in the foreground is employed as the source of a moment of musical wit, the broader level here consisting of an intensification of the comic gesture. In the Schubert song the role of ambiguity is more deep-seated, more subtle, and might be termed "ambiguity as structural premise." 4

Foreground harmonic ambiguity of a yet subtler order with implications on a deeper structural level are present, I believe, in the two central modulating episodes of Chopin's Prelude No. 17 in A-flat. Formally, the prelude is a straightforward rondo, consisting of five sections: A (mm. 3-18), B (mm. 19-34), $\mathrm{A}^{1}$ (mm. 35-42), $\mathrm{C}$ (mm.43-64), and $\mathrm{A}^{2}$ (mm. 65-80). Without its two-measure introduction, the A section or rondo theme consists of a perfectly symmetrical sixteen-measure double period, with clearly articulated half and authentic cadences in measures eight and sixteen. In common with many rondos, the second A section presents only part of the principal theme, in this instance the
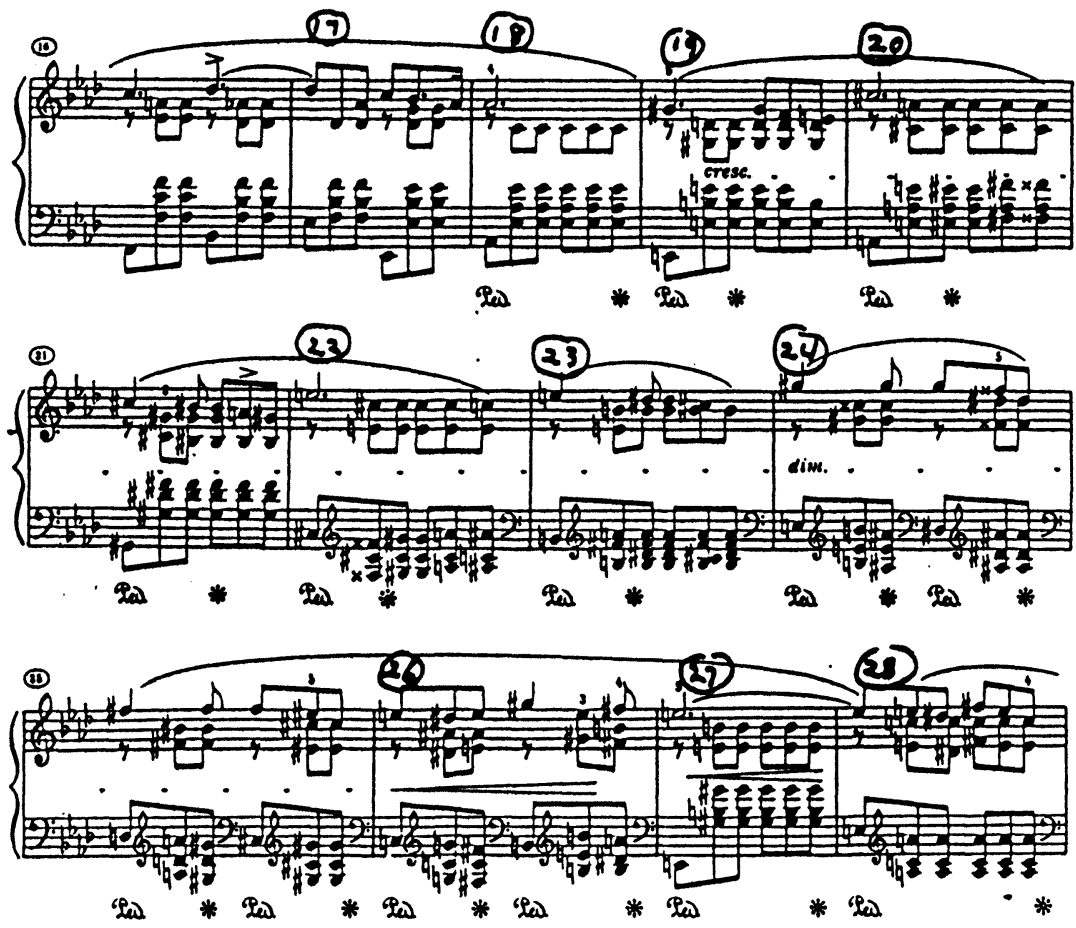

Example 3: Chopin, Prelude in A-flat, op.28, no.17, mm.16-57.

4 The phrase comes from David Epstein's Beyond Orpheus (1979), in which the role of structural ambiguity in such large-scale works as Schumann's Symphony No 3 (Rhenish) and Brahms's Symphony No. 2 is fully elucidated. 

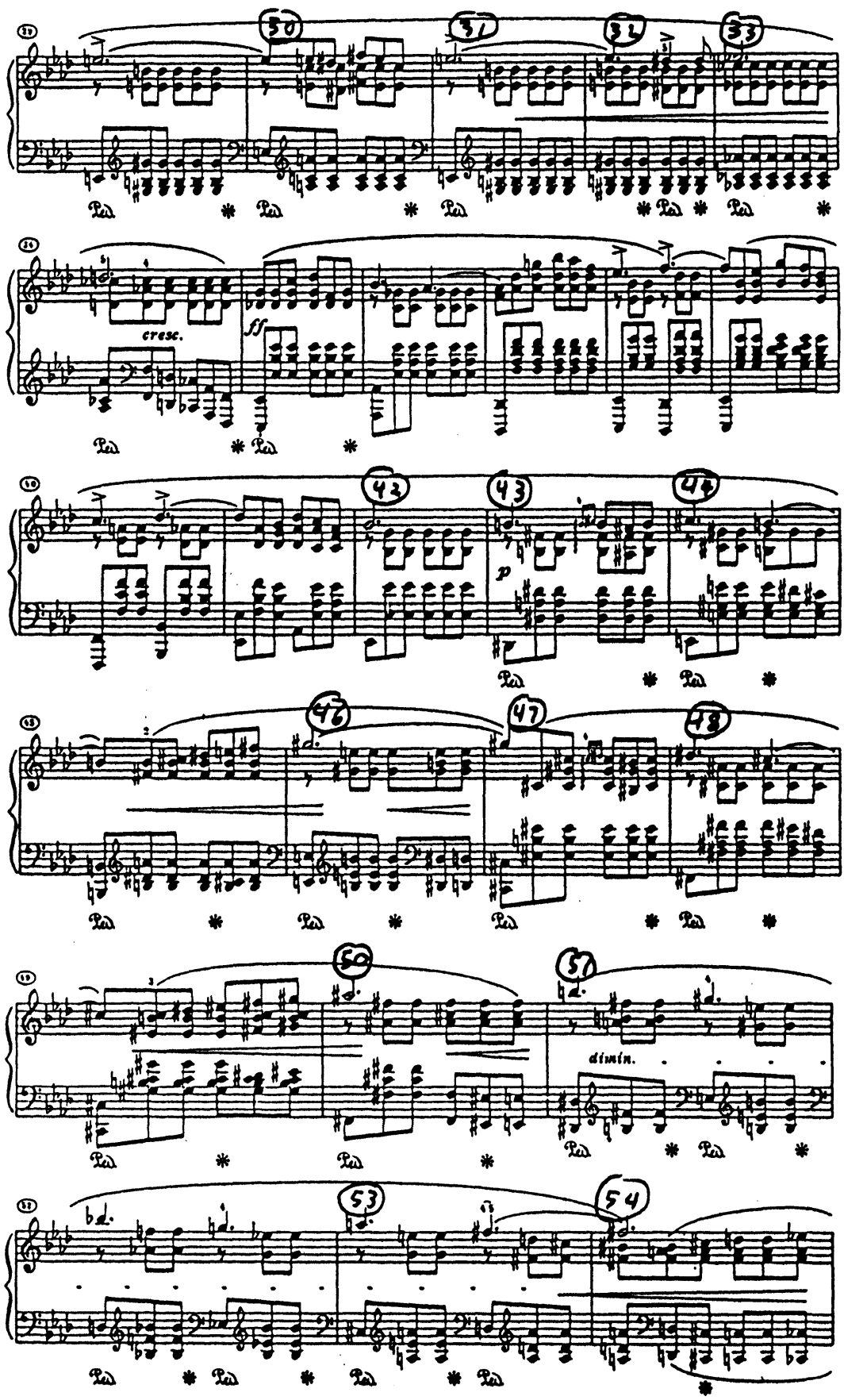
first half; and the final A section is extended by a short coda, with the entire final presentation of the rondo theme sounded over a low A-flat pedal point given eleven times.

The central points of interest here, however, lie in the two modulatory episodes. Unlike the two previous examples, these episodes are treated as being different from each other and are not presented as direct repetitions of the same music. In context they provide the necessary element of contrast essential to the rondo from, contrasting both with the main rondo theme and with each other. However, even a cursory examination of these episodes suggests certain similarities between them (see Example 3, mm. 19- 27 and 43-54). For one thing, the piano texture remains essentially consistent throughout the entire prelude, even persisting through these contrasting episodes. Moreover, each of the episodes is constructed around modulating harmonic sequences, and each features a rising sixth as a prominent and characteristic melodic interval. Both episodes include striking harmonic passages, typical of Chopin in a modulatory mood, which approach the type of "harmonic parenthesis" found in other works of Chopin. ${ }^{5}$ Since both episodes conclude with a return to a point harmonically congruent with their openings (tonic and dominant respectively), they constitute parallel digressionary flights of fantasy or passages of harmonic speculation, which move outward and away from the stability of the initial idea to explore new realms before returning to their original point of departure to continue the musical discourse. Despite these similarities in general character and types of harmonic procedures employed, the contrastive function of the two passages within the formal structure remains intact. For one thing the actual harmonic progressions in each of the episodes are quite different: the first is based upon a sequence which rises by thirds and is followed by a stepwise descent; the second is based upon a sequence that rises by step and is followed by a chromatic descent. On the immediate foreground level, the first episode features modulation through augmented-sixth chords ( $\mathrm{mm} .20-27$ ), while the second is concerned principally with Neapolitan harmony. ${ }^{6}$

On the deeper harmonic level, however, it can be shown that both episodes derive actually from a common harmonic source, the specific formulation of each episode resulting from taking a different harmonic fork along the same fundamental path or underlying foreground harmonic conception. The first episode (Example 3, mm. 19-34) begins in A major, the enharmonic Neapolitan, and is constructed as a three-member sequence that uses augmented-sixth chords to

5 The term was first used by Gerald Abraham (1939), and is treated more extensively in such recent writings as Richard Parks (1976); Cheryl Noden-Skinner (1984); and Jim Samson (1985).

6 It is indeed curious that the harmonic analysis of these two episodes given by Leichtentritt (1921) should be so flawed. The first episode is cited as being entirely within the tonal orbit of $E$ major, and no mention is made of the augmented-sixth harmony that animates both of the sequences. Similarly, the Neapolitan colouring of the second sequence is ignored, as is any harmonic activity that is inconveniently complex. 


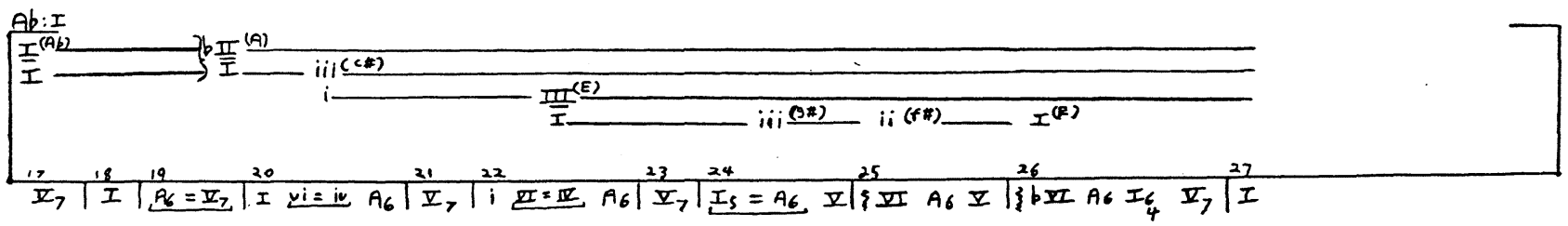

Example 3a: Chopin, Prelude in A-flat, mm.176-27, graph analysis.

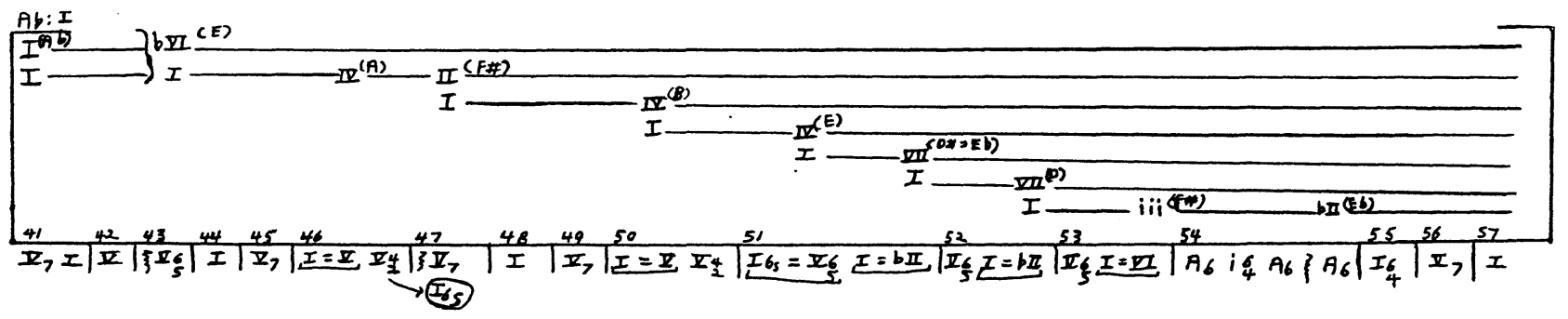

U Example 3b: Chopin, Prelude in A flat, mm.41-57, graph analysis. 
rise by thirds, tonicizing A major, C-sharp minor, and $\mathrm{E}$ major as I, iii, and V of a background key to A major. E major is confirmed as the ultimate harmonic goal by a further tonicization of G-sharp, F-sharp, and again E major, the proper scale degrees for $\mathrm{E}$ major as momentary control tonic (see the graph analysis ${ }^{7}$ in Example 3a). Harmonically then, the first episode is a composite of two devices: sequential modulation up by thirds using augmented- sixth chords and sequential modulation down by step, also using augmented-sixth chords. It is worth noting here that the initial move to the Neapolitan (A major) was accomplished by means of yet another augmented-sixth chord. In fact,the whole episode consists of a digression based upon this one essential foreground element.

Viewed from this perspective, the second episode is harmonically rather different. Whereas the first episode begins in the Neapolitan and exploits augmentedsixth chords, the second begins in bVI (the augmented-sixth region harmonically) and is principally concerned with achieving a sharp-side climax in measure 51 and a corresponding fall using Neapolitan harmony (see graph analysis in Example 3b). Thus where the first episode is concerned with augmented-sixth chords, the second is concerned with the development of Neapolitan relationships.

Beneath this difference, however, lies the common fundamental generating conception, one that is only present by veiled implication and is perhaps best revealed by pressing the two passages against a severely diatonic template. Each of the sequential modulations which rise by thirds (mm. 19-24) is achieved, from a purely diatonic point of view, through an aberration from the "normal"

7 The method of graphic analysis used here is one developed by Leland Smith (1963) in which Schenkerian principles of reductive layer analysis are fused with elements of traditional Roman numeral analysis. Since the approach to harmonic analysis may not be widely familiar, a few of those elements likely to cause confusion should be mentioned here. Harmonic activity is graphically separated into three levels, which correspond in a basic way to the familiar Fordergrund, Mittelgrund, and Hintergrund. The crucial aspect here, one over which many theoretical wars can easily be waged, is the showing in the middle level of not only the specific keys indicated in the music (shown intervalically as related to a specific functioning tonic), but also the specific tonic out of which a subsequent modulation is heard to arise. Thus in Example 3a the rising thirds in measures 19-22 (A major, C-sharp minor, E major) are shown as a sequence in which each subsequent key is heard as stemming from the immediately preceding key: hence the added levels in the middle level. The subsequent sequence in measures $24-26$, by contrast, is shown as having a common background tonic of E major: hence the single line which shows the aural dependency of the three keys (G-sharp minor, F-sharp minor, and E major) upon the common tonic. Another point of difference with more common analytical approaches is the use of a symbol (a broken or "wavy" line [ 2$]$ ) to indicate in the foreground those situations in which key change takes place without a pivot chord, a symbol lacking in traditional Roman numeral analysis. It should also be noted that all so-called "secondary dominant" functions are in this approach shown as brief modulations. The charting of modulatory activity in the allimportant middle ground can be shown through the use of "tonic guide tones" (see Example $2 \mathrm{~d}$ and Examples 3c-3f) which approach Schenkerian analysis format with the indication of lesser and more important tonal centres through the use of lines and different note values. The approach is fully developed in Smith's book, which now serves as a text for harmonic analysis courses in several North American universities. 

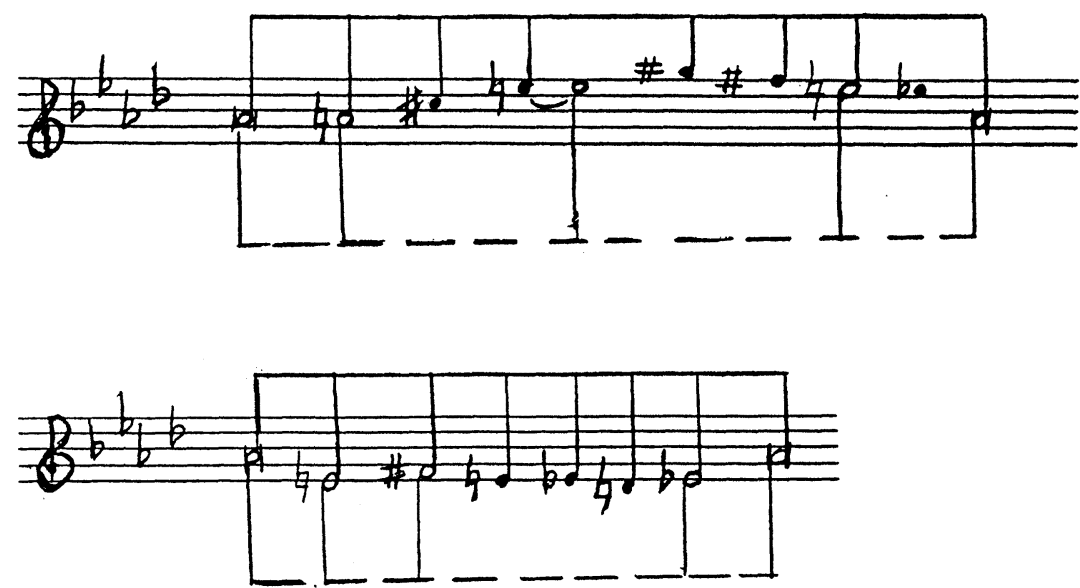

Example 3c: Chopin, Prelude in A-flat, mm.19-35 and 42-65, tonic guide tones.

resolution of dominant-seventh harmony. Thus, for example, the augmentedsixth chord at the very end of measure twenty should lead to D major, (down the circle of fifths, as it were), instead of being deflected toward C-sharp minor. Correspondingly, the end of measure twenty-two should led to $\mathrm{F}$ major and measure twenty-four to A-flat major. Once the decision has been made to treat these erstwhile dominants as augmented-sixth chords-the critical fork along the path to harmonic fantasy land-the new idea becomes self-generating, reaching eventually to G-sharp minor before falling back to $E$ major. This same core idea of deflected dominants is also present behind the initial sequence of the second episode. In measure forty-six the final chord, a V4/2 of A, is made to resolve, not to its expected tonic, but to the dominant of A major's relative minor or, as it emerges, E major's supertonic (F-sharp), here brigthened by a tierce de Picardie, which takes the music far to the sharp side and to the climax of the episode (m. 51). Thus both of these sequences are created out of deflections of the expected resolutions of dominant-seventh chords: in the first episode the dominant-seventh are treated as augmented-sixth chords; in the second the bass of the expected I6 chord is treated as V/vi.

The second component of these twinned episodes concerns the treatment of descending stepwise motion. In the first instance (mm. 24-26), Chopin, clearly concerned to confirm E major as tonic, tonicizes G-sharp minor and F-sharp minor, leaving essentially untouched the possibility of an implied tonicization of each chromatic scale step, in which each chord is approached as a dominantseventh and quitted as an augmented-sixth chord. By omitting the easily available seventh in the second half of measures twenty-four and twenty-five, Chopin asserts the primacy of the whole step descent rather than the fully chromatic descent that is equally possible. In the second episode, however, what 

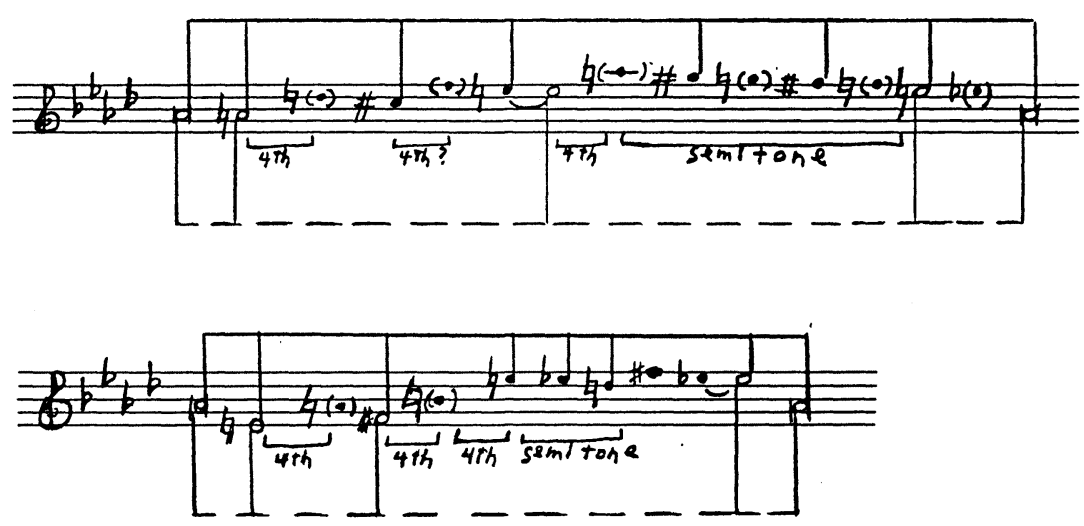

Example 3d: Chopin, Prelude in A-flat, mm.19-35 and 42-65. tonic guide tones (original conception).

was possible the first time but not made explicit is now revealed. Measures fiftyone to fifty-three trace a chromatic stepwise descent in which each step is explicitly tonicized (see Example 3d).

Both episodes, then, consist of a fantasy-style treatment of two central ideas: (1) a rapid decent by fifths, deflected to mediant and rising stepwise motion; and (2) a descending chromatic scale, harmonized in groups of two to create whole-step motion, but also harmonized chromatically. The full structural implications of potential ambiguity here reach beyond that of the two previous examples and resemble the type of ambiguity which Empson describes as type four: an "ambiguity which talks about one thing and implies several ways of judging or feeling about it," and "a complicated state of indecision which involves much estimating of probabilities and is less ignorance than ordered suspension of judgement" (1953: 125 and 16). Here, as in the two previously discussed examples, the image of the fork in the road, of paths taken and retaken to different expressive ends, can be helpful in understanding Chopin's approach to composition, at least in these two short passages.

How much Chopin was conscious of the commonality between the two passages and how much he was responding to a deeply imbedded instinct cannot, of course, be known.But perhaps instructive to note is that it is from a close reading of the foreground - that somewhat neglected aspect of contemporary analysisthat the elements which link these two passages can be uncovered. Jim Samson, in his recent detailed study of all Chopin's music states that "chord-by-chord 'functional' analysis of Chopin's harmony has largely been discredited, and that "much of his rich chromatic elaboration can be properly perceived as ornament, however profuse, or prolongation, however extended." In large measure Samson is no doubt correct, but I am more and more convinced of the truth of Wallace Berry's observation in Structural Functions in Music (1976: 37) when he states: 
"Analysis is far too often content with delineation of broad structure as THE structure, leaving untreated the vital, arresting patterns by which the great work of music projects and extends in time the prototypical basis." In this instance, it is the ambiguous properties inherent in the harmonic foreground which appear to have lead Chopin to explore two different forks in his basic compositional path. In this he could have said with Frost, "I have taken the path less traveled by, and that has made all the difference" (Frost 1970: 27).

\section{REFERENCES}

ABRAHAM, Gerald

1939: Chopin's Musical Style., London: Oxford University Press.

BERRY, Wallace

1976: Structural Functions in Music. New York: Dover.

EMPSON, William

1953: Seven Types of Ambiguity. New York: New Directions.

EPSTEIN, David

1979: Beyond Orpheus: Studies in Musical Structure. Cambridge, Mass.: MIT Press.

FROST, Robert

1970: "The Road Not Taken," in Walter Blair et al., ed., The Literature of the United States. Vol. 3: 267-27. New York: Scott, Foresman, and Co.

LEICHTENTRITT, Hugo

1921: Analyse der Chopi'schen Klavierwerke. Berlin: Mar Hesses.

NODEN-SKINNER, Cheryl

1984: "Tonal Ambiguity in the Opening Measures of Selected Works by Chopin," College Music Symposium, 24: 28-34.

PARKS, Richard

1976: "Voice Leading and Chromatic Harmony in the Music of Chopin," Journal of Music Theory, 20: 189-214.

SAMSON, Jim

1985: The Music of Chopin. London: Routledge and Kegan Paul.

SMITH, Charles J.

1986: "The Functional Extravagance of Chromatic Chords," Music Theory Spectrum, 8: 94-139.

SMITH, Leland

1963: Handbook of Harmonic Analysis. Palo Alto: San Andreas Press.

THOMSON, William

1983: "Functional Ambiguity in Musical Structure," Music Perception, 1: 3-27. 